\title{
BARIATRIC SURGERY AS A SAFE AND EFFECTIVE INTERVENTION FOR THE CONTROL OF COMORBIDITIES IN OLDER ADULTS
}

\author{
A cirurgia bariátrica como intervenção segura e \\ eficaz para o controle de comorbidades em idosos
}

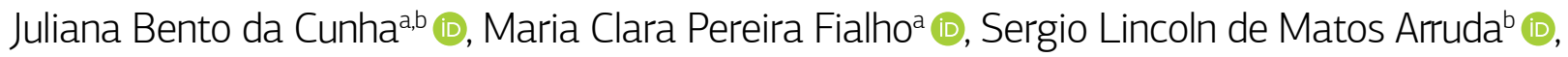 \\ Otávio Toledo Nóbrega ${ }^{\circledR}$, Einstein Francisco Camargos ${ }^{\mathrm{a}}$ (
}

INTRODUCTION: In addition to being associated with worsening of diseases related to metabolic syndrome and musculoskeletal disorders, obesity in older adults increases the risk of falls, frailty syndrome, depression, and dementia, with consequent functional loss. Among all treatments available, bariatric surgery is an option for eligible patients. OBJECTIVES: To discuss aspects related to the safety and benefits of bariatric surgery for the control or remission of comorbidities in older adults. METHODS: This literature review was carried out in databases, using the following keywords: bariatric surgery and elderly or aged or older adult and comorbidities or safety. We included clinical trials, observational studies, comparative studies, and reviews that evaluated the effect of bariatric surgery on the control or remission of comorbidities in older adults. RESULTS: In recent years, several studies have evidenced not only control or remission of comorbidities, such as diabetes, hypertension, and sleep apnea syndrome, but also a low rate of complications, similar to those observed in young people. CONCLUSIONS: Based on the results of these studies, bariatric surgical procedures can be indicated for eligible older adults, without age restriction, taking into account functional and life expectancy aspects.

KEYWORDS: bariatric surgery; aged; comorbidity; postoperative complications; mortality.

INTRODUÇÃO: A obesidade no idoso, além de estar associada à piora de doenças relacionadas à síndrome metabólica e a distúrbios osteoarticulares, aumenta o risco de quedas, síndrome de fragilidade, depressão e demência, com consequente perda de funcionalidade. Entre todos os tratamentos disponíveis, a cirurgia bariátrica é uma alternativa em pacientes elegíveis. OBJETIVOS: Discutir aspectos relacionados à segurança e aos benefícios da cirurgia bariátrica para o controle ou a remissão de comorbidades no idoso. METODOLOGIA: Foi realizada revisão de literatura em bases de dados utilizando os seguintes descritores: bariatric surgery and elderly or aged or older adult and comorbidities or safety. Foram incluídos ensaios clínicos, estudos observacionais, estudos comparativos e revisões que avaliaram o efeito da cirurgia bariátrica no controle ou na remissão de comorbidades em idosos. RESULTADOS: Nos últimos anos, vários estudos têm demonstrado não apenas controle ou remissão de comorbidades como diabetes, hipertensão e síndrome da apneia do sono, mas também reduzida taxa de complicações, semelhante à observada em jovens. CONCLUSÕES: Com base nos resultados desses estudos, há espaço para que procedimentos de cirurgia bariátrica sejam indicados a idosos elegíveis, sem limite de idade, considerando também aspectos funcionais e de expectativa de vida.

PALAVRAS-CHAVE: cirurgia bariátrica; idoso; comorbidade; complicações pós-operatórias; mortalidade.

aGraduate Program in Medical Sciences, School of Medicine, Universidade de Brasília - Brasília (DF), Brazil.

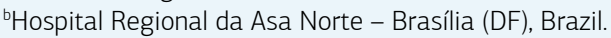

Correspondence data

Juliana Bento da Cunha - Hospital Regional da Asa Norte, Ambulatório de Geriatria e Gerontologia - SMHN Quadra 02 - CEP: $70710-100$ - Brasília (DF), Brasil. E-mail: julianabcunha@gmail.com

Received on: 03/30/2020. Accepted on: 07/29/2020

https://doi.org/10.5327/Z2447-212320202000037 


\section{INTRODUCTION}

According to the Brazilian Ministry of Health, one in every five adults in the country is obese, and the prevalence of obesity increased by $70 \%$, from 11.80 to $19.80 \%$, between 2006 and 2018. ${ }^{1}$ Among Brazilians aged 65 years or older, the prevalence of obesity is $18.30 \%$ in men and $23.60 \%$ in women. ${ }^{1}$ Also, obesity shows an overall increasing trend among the older population, reaching epidemic proportions. Europe experienced an increase from $17.50 \%$ in 2005 to $19.20 \%$ in 2013, and among the ten countries assessed, only Spain reduced the number of obese people over the years. ${ }^{2}$

In addition to being associated with worsening of diseases related to metabolic syndrome and musculoskeletal disorders, obesity in older adults increases the risk of falls, frailty syndrome, depression, and dementia, with consequent functional loss..$^{3-6}$

The therapeutic strategy for obesity should be multifactorial, involving lifestyle changes, psychological and behavioral approaches, and, if necessary, use of a drug or surgical therapy with an appropriate multidisciplinary follow-up.

Over the past decade, bariatric surgery has increasingly become a therapeutic option for older individuals. According to the World Health Organization (WHO) and the Brazilian Ministry of Health, bariatric surgery is indicated for patients with body mass index (BMI) greater than $35 \mathrm{~kg} / \mathrm{m}^{2}$ who have complications such as sleep apnea syndrome (SAS), systemic arterial hypertension (SAH), diabetes mellitus (DM), dyslipidemia, and degenerative joint diseases, as well as for patients with BMI greater than or equal to $40 \mathrm{~kg} / \mathrm{m}^{2}$ who were not able to lose weight after two years of clinical treatment (including the use of medication), ${ }^{7}$ regardless of age.

In Brazil, the number of bariatric surgeries has been growing yearly. In 2013, 468,609 surgeries were performed globally ( $95.70 \%$ were laparoscopies), nearly $20 \%$ of them in Brazil. ${ }^{8}$ According to data from the Brazilian Society for Metabolic and Bariatric Surgery, the number of surgeries performed in the country increased by $42.70 \%$, from 72 thousand to 105 thousand, between 2012 and 2017. ${ }^{9}$ Among the patients submitted to bariatric surgery, older adults represent 6 to $10 \% .{ }^{10-12}$

To be eligible for bariatric surgery, older adults follow the same criteria established for individuals under 65 years of age ${ }^{7}$ and includes assessing of functional capacity and the impact of the procedure on the quality of life, besides a multidisciplinary risk/benefit evaluation of the procedure. ${ }^{13}$ The preoperative evaluation should go beyond the clinical and psychosocial status, aiming at functional capacity and the potential quality of life improvement, in a context of life expectancy greater than 10 years. ${ }^{13}$

Bariatric surgical procedures lead to weight loss by being restrictive (reducing the size of the stomach and, consequently, the volume of food consumed), malabsorptive (leading to low absorption of nutrients), or a combination of both mechanisms, the so-called mixed techniques. ${ }^{14}$ The most common types are gastric bypass, vertical sleeve gastrectomy, adjustable gastric banding, and biliopancreatic diversion with duodenal switch. ${ }^{15}$

Even though vertical sleeve gastrectomy is the most common in North America, most data available in the literature involve gastric bypass, which is the type of surgery most studied and performed in the world. ${ }^{16}$ In this surgery, the deviation of food flow produces changes in intestinal hormones that promote satiety and suppress hunger. Patients submitted to this surgery lose 60 to $80 \%$ of their initial overweight. The procedure may lead to vitamin and mineral deficiencies in the long term. ${ }^{17,18}$

Despite the clear indications and benefits of bariatric surgery for non-older individuals, this approach is still criticized and questioned by doctors and other professionals who deal with older people. Faced with this reality, the current work aimed to conduct a narrative review and discuss aspects related to the safety and benefits of bariatric surgery for the control or remission of comorbidities in older adults based on national and international scientific literature, and promote the debate between geriatricians and gerontologists.

\section{METHODS}

Between July 11 and 15, 2020, we carried out a literature review in PubMed/MEDLINE, Scopus, Latin American and Caribbean Health Sciences Literature (LILACS), and Scientific Electronic Library Online (SciELO), using the following keywords: bariatric surgery and elderly or aged or older adult and comorbidities or safety. We included clinical trials, observational studies, comparative studies, and reviews that evaluated the effects of any bariatric surgical procedure on the control or remission of comorbidities in older adults, even when comparing them with lower age groups, as well as aspects relating to safety. The search was limited to articles in English, Spanish, and Portuguese. No restriction was placed regarding the date of publication, in an attempt to identify the greatest possible number of publications 
in the field. Studies that evaluated only other outcomes and did not include the control of comorbidities and/or safety were excluded. As a complement, we conducted manual searches to retrieve relevant articles from the lists of references of studies obtained in the main literature searches.

\section{RESULTS}

The initial search identified 1,089 articles, from which 1,052 were excluded, as, based on the title and abstract, they did not specifically address the issue under study. Among the 37 remaining papers, 15 did not meet all inclusion criteria, and 2 were duplicates (Figure 1). Only two of the selected articles ${ }^{19-38}$ differentiated groups of individuals aged 70 years or older, ${ }^{23,24}$ and four considered older individuals those aged 55 years or older, ${ }^{29,32,33,38}$ a common fact among studies on bariatric surgery in the older population. Five of the articles included are literature reviews. ${ }^{26,30,32,36,37}$

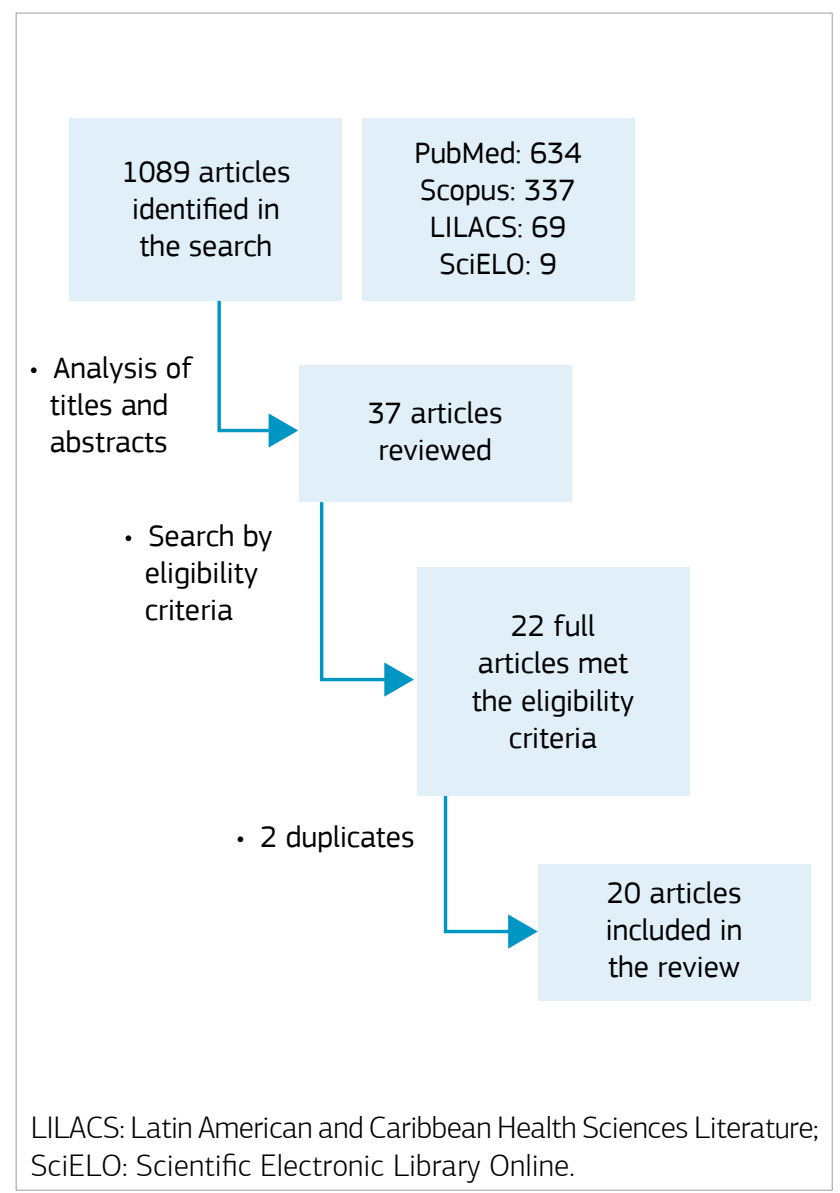

Figure 1 Literature search results.

\section{DISCUSSION}

\section{Benefits}

Overall, the studies selected for this literature review point to a large amount of scientific evidence indicating the beneficial effects of bariatric surgery in older adults. The percentage of total weight loss was between 25 and $35 \%$ of the weight before surgery. ${ }^{24,33}$ The percentage of excess weight lost (the difference between pre-surgery weight and the ideal weight according to the BMI of $25 \mathrm{~kg} / \mathrm{m}^{2}$ ) ranged from 39 to $76 \%$. The numbers were lower after procedures such as adjustable gastric banding $(39.10 \%)^{32}$ and among individuals older than 70 years (from 47.10 to $50.40 \%$ ). ${ }^{23,24}$

In addition to weight loss, significant benefits related to clinical and metabolic parameters were found in the older population. The literature has presented concordant results, showing remission, albeit less expressive than that in young people, of obesity-related comorbidities, such as DM, SAH, and dyslipidemia, regardless of the surgical technique used. ${ }^{22,26,27}$ DM improvement and/or remission ranged from 50 to $100 \%$, while for $\mathrm{SAH}$, these values varied from 42 to $98 \%$ in older individuals after surgery. Three other reviews confirmed the same benefits concerning these comorbidities. ${ }^{32,36,37}$

Other comorbidities often found in older adults and that improved with the surgical procedure are SAS, reported in 12 of the studies analyzed; ${ }^{19,20,22,25,27,28,31-35,38}$ joint pain, in 7 studies; $;^{19,20,22,25,32,35,38}$ and osteoarthritis, in 2 studies. ${ }^{28,34}$ Among the metabolic parameters, bariatric surgery reduced glycated hemoglobin, ${ }^{39}$ total cholesterol, and triglycerides, ${ }^{39,40}$ and increased high-density lipoprotein (HDL)-cholesterol. ${ }^{40}$ Likewise, these benefits were identified among Brazilian older adults in a study conducted by our group in Brasília, also included in this review. ${ }^{29}$

Another significant outcome for the older population is the impact of the surgical procedure on reducing the number of drugs taken. O'Keefe et al. found a $60 \%$ reduction in the average number of medications used per older adults after one year of surgery (mean decrease from 8.10 to 4.90 drugs). ${ }^{41}$ Various studies have confirmed this finding, with a reduction in the number of medications around $40 \% .{ }^{42,43}$ Interestingly, older people seem to have more benefits regarding the decrease in the number of medications than young individuals one year after surgery. ${ }^{44}$ Australian research showed a decrease in the use of antihypertensive drugs, hypoglycemic agents, lipid-lowering drugs, and analgesics after the procedure. ${ }^{19}$ This finding was also identified in a previous study we conducted involving older Brazilians, which confirmed the reduction in the use of drugs, despite the increase in vitamin and mineral supplements. ${ }^{29}$ 
In addition to the benefits mentioned, we also highlight the improvement in the quality of life. Four studies have evaluated this aspect. ${ }^{19,22,25,38}$ In general, the individuals reported improvement in the quality of life after bariatric surgery, associating it with physical function, perceived health, and vitality. On the other hand, according to a French study, young people seem to experience a more significant impact on their quality of life post-surgery than older adults. ${ }^{22}$

Despite being the cornerstone of geriatric assessments, few studies have addressed the possible benefit of bariatric surgery to the functional capacity of older adults. Because chronological age is not always parallel with biological age, future research on this topic must investigate functional capacity as an outcome. We found no studies that evaluated this aspect in the postoperative period of bariatric surgery. In Brazil, Pajecki et al. analyzed a sample of 40 older adults (mean age of 64.15 years) and identified dependence in performing activities of daily living before surgery in approximately $50 \%$ of them, with the greatest limitation involving the increase in BMI and not the age greater than 65 years..$^{45}$ Thus, the benefit for this clinical and functional variable remains unclear.

\section{Safety}

The main concern might be more related to doubts about the safety of bariatric surgery than to its benefit for the older population. Despite the plausible worry about this surgical procedure in older individuals, a systematic review of 38 studies compared the safety of bariatric surgery among older and young people, revealing that most studies found no differences in early mortality or the rates of complications between groups. ${ }^{3}$ The other studies included in the review showed varying rates of complications associated with the type of procedure and even the surgeon's experience. A recent systematic review comparing complications of gastric bypass and vertical sleeve gastrectomy among young and older $(>65$ years of age) individuals found no significant difference in the incidence of complications between the groups ${ }^{46}$ or even when comparing patients submitted to distinct types of procedure, regardless of age. ${ }^{47}$

Among the complications related to bariatric surgery in older adults, those associated with the surgical procedure, particularly vomiting, occlusion, abscess, stenosis, and bleeding, stand out. Non-surgical complications include venous thromboembolism, anemia, malnutrition, and infection. . $^{11,12,40,48}$

A survey of the International Federation for the Surgery of Obesity and Metabolic Disorders reported information of patients from 31 countries submitted to bariatric surgery between 2013 and 2015. It revealed that gastric bypass was performed in $49.40 \%$ of cases, vertical sleeve gastrectomy in $40.70 \%$, gastric banding in $5.50 \%$, and other procedures in less than $1 \% .{ }^{16}$ Despite the complications described in gastric bypass and vertical sleeve gastrectomy, the data available is not clear enough to determine which surgical technique is superior. However, Pechman et al. suggest that vertical sleeve gastrectomy could be the most suitable for older adults with risk factors in specific organs, due to increased adverse effects, such as acute kidney failure and myocardial infarction, in individuals older than 70 years submitted to Rouxen-Y gastric bypass. ${ }^{48}$ Another study that compared older and young people who underwent gastric bypass and vertical sleeve gastrectomy revealed that the group with higher age showed no increased intra- or postoperative risk. ${ }^{44}$

An important aspect is the long-term follow-up of these individuals. The deficit in the process of nutrient absorption, coupled with non-adherence to the recommendations for supplementation, is a critical causal factor for their nutritional deficiency after bariatric surgery. The primary nutritional deficiencies after bariatric surgery in older adults and young people are associated with the decrease in food intake or the reduction in the area of nutrient absorption caused by the surgery. ${ }^{49}$ Levels of vitamin B12, folate, iron, thiamine, vitamin D, calcium, zinc, and copper should be monitored. ${ }^{49,50}$ Bergeat et al. revealed that, after 24 months, iron and vitamin B12 deficiencies were less prevalent among older adults than in the younger group. ${ }^{22}$ Monitoring patients submitted to bariatric surgery is crucial to treat early deficiencies and avoid complications caused by a lack of micronutrients.

\section{CONCLUSION}

In line with the worldwide growth in obesity prevalence, bariatric surgeries tend to increase proportionally among the older population. The literature is convergent and points to significant clinical and metabolic benefits in the postoperative period, including the control of DM, SAH, SAS, and osteoarthritis, as well as the reduction in drug use and levels of total cholesterol, triglycerides, and glycated hemoglobin. Regarding safety, the surgery is associated with mortality similar to that of younger individuals and low complication rates. Bariatric surgical procedures can be indicated for eligible older adults, without age restriction, considering a good functional evaluation and life expectancy. These individuals should also be regularly monitored, and long-term studies are necessary to identify possible late complications that have not been investigated yet. 


\section{CONFLICTS OF INTEREST}

The authors declare no conflicts of interest.

\section{FUNDING}

None

\section{AUTHORS' CONTRIBUTION}

JBC, MCMPF, SLMA, OTN, EFC: conceptualization, methodology, data curation, formal analysis. JBC, MCMPF, SLMA, EFC: investigation, writing - original draft. JBC, OTN, EFC: writing - review \& editing, supervision. All authors have read and approved the final version of the article.

\section{REFERENCES}

1. Brasil. Ministério da Saúde. Vigitel Brasil 2018: Vigilância de fatores de risco e proteção para doenças crônicas por inquérito telefônico. Brasília: Secretaria de Vigilância em Saúde. Departamento de Análise em Saúde e Vigilância de Doenças não Transmissíveis; 2019.

2. Peralta M, Ramos M, Lipert A, Martins J, Marques A. Prevalence and trends of overweight and obesity in older adults from 10 European countries from 2005 to 2013. Scand J Public Health. 2018;46(5):52229. https://doi.org/10.1177/1403494818764810

3. Haywood C, Sumithran P. Treatment of obesity in older persons a systematic review. Obes Rev. 2019;20(4):588-98. https://doi. org/10.1111/obr.12815

4. Samper-Ternent R, Al Snih S. Obesity in older adults: epidemiology and implications for disability and disease. Rev Clin Gerontol. 2012;22(1):1034. https://doi.org/10.1017/s0959259811000190

5. Allison DB, Newcomer JW, Dunn AL, Blumenthal JA, Fabricatore AN, Daumit GL, et al. Obesity among those with mental disorders. A National Institute of Mental Health Meeting report. Am J Prev Med. 2009;36(4):341-50. https://doi.org/10.1016/j.amepre.2008.11.020

6. de Wit L, Luppino I, van Straten A, Penninx B, Zitman F, Cuijpers P. Depression and obesity: A meta-analysis of community-based studies. Psychiatry Res. 2010;178(2):230-5. https://doi.org/10.1016/j. psychres.2009.04.015

7. Brasil. Ministério da Saúde. Portaria no 424, de 19 de março de 2013. Redefine as diretrizes para a organização da prevenção e do tratamento do sobrepeso e obesidade como linha de cuidado prioritária da Rede de Atenção à Saúde das Pessoas com Doenças Crônicas. Diário Oficial da Únião. n. 54. Brasília: Ministério da Saúde; 2013.

8. Angrisani L, Santonicola A, lovino P, Formisano G, Buchwald H, Scopinaro N. Bariatric surgery worldwide 2013. Obes Surg. 2015;25(10):182232. https://doi.org/10.1007/s11695-015-1657-z

9. Sociedade Brasileira de Cirurgia Bariátrica e Metabólica. Boletim da Sociedade Brasileira de Cirurgia Bariátrica e Metabólica. ed. 53. São Paulo: Sociedade Brasileira de Cirurgia Bariátrica e Metabólica; 2018.

10. Dorman RB, Abraham AA, Al-Refaie WB, Parsons HM, Ikramuddin S, Habermann EB. Bariatric surgery outcomes in the elderly: an ACS NSQIP study J Gastrointest Surg. 2012;16(1):35-44; discussion 44. https://doi.org/10.1007/s11605-011-1749-6

11. Ritz P, Topart P, Benchetrit S, Tuyeras G, Lepage B, Mouiel J, et al. Benefits and risks of bariatric surgery in patients aged more than 60 years. Surg Obes Relat Dis. 2014;:S1550-7289(14)00004-5. https:// doi.org/10.1016/j.soard.2013.12.012

12. Gebhart A, Young MT, Nguyen NT. Bariatric surgery in the elderly: 2009-2013. Surg Obes Relat Dis. 2015;11(2):393-8. https://doi. org/10.1016/j.soard.2014.04.014

13. Batsis JA, Dolkart KM. Evaluation of older adults with obesity for bariatric surgery: geriatricians' perspective. J Clin Gerontol Geriatr. 2015;6(2):45-53. https://doi.org/10.1016/j.jcgg.2015.01.001

14. Wolfe BM, Kvach E, Eckel RH. Treatment of obesity: weight loss and bariatric surgery bruce. Circ Res. 2016;118(11):1844-55. https://doi. org/10.1161/CIRCRESAHA.116.307591

15. Angrisani L, Santonicola A, lovino P, Vitiello A, Higa K, Himpens J, et al. IFSO Worldwide survey 2016: primary, endoluminal, and revisional procedures. Obes Surg. 2018;28(12):3783-94. https://doi.org/10.1007/ s11695-018-3450-2

16. Welbourn R, Pournaras DJ, Dixon J, Higa K, Kinsman R, Ottosson J, et al. Bariatric surgery worldwide: baseline demographic description and one-year outcomes from the second IFSO global registry report
2013-2015. Obes Surg. 2018;28(2):313-22. https://doi.org/10.1007/ s11695-017-2845-9

17. Khwaja HA, Bonanomi G. Bariatric surgery: techniques, outcomes and complications. Curr Anaesth Crit Care. 2010;21(1):31-8. https://doi. org/10.1016/j.cacc.2009.10.005

18. Elder KA, Wolfe BM. Bariatric surgery: a review of procedures and outcomes. Gastroenterology. 2007;132(6):2253-71. https://doi. org/10.1053/j.gastro.2007.03.057

19. Taylor CJ, Layani L. Laparoscopic adjustable gastric banding in patients $\geq 60$ years old: Is it worthwhile? Obes Surg. 2006;16:1579-83. https:// doi.org/10.1381/096089206779319310

20. Busetto L, Angrisani L, Basso N, Favretti F, Furbetta F, Lorenzo M, et al. Safety and efficacy of laparoscopic adjustable gastric banding in the elderly. Obesity (Silver Spring). 2008;16(2):334-8. https://doi. org/10.1038/oby.2007.85

21. Pequignot A, Prevot F, Dhahri A, Rebibo L, Badaoui R, Regimbeau JM. Is sleeve gastrectomy still contraindicated for patients aged $Z 60$ years? A case-matched study with 24 months of follow-up. Surg Obes Relat Dis. 2015;11(5):1-6. https://doi.org/10.1016/j.soard.2014.11.015

22. Bergeat D, Lechaux D, Ghaina A, Thibault R, Bouygues V. Postoperative outcomes of laparoscopic bariatric surgery in older obese patients: a matched case-control study. Obes Surg. 2017;27(6):1414-22. https:// doi.org/10.1007/s11695-016-2517-1

23. Nor Hanipah Z, Schauer PR. Reply letter to the editor "The Outcome of Bariatric Surgery in Patients Aged 75 years and Older". Obes Surg. 2018;28(10):3310-1. https://doi.org/10.1007/s11695-018-3457-8

24. Parmar C, Mahawar KK, Carr WR, Schroeder N, Balupuri S, Small PK. Bariatric surgery in septuagenarians: a comparison with $<60$ year olds. Obes Surg. 2017;27(12):3165-9. https://doi.org/10.1007/ s11695-017-2739-x

25. Lainas P, Dammaro C, Gaillard M, Donatelli G, Tranchart H, Dagher I. Safety and short-term outcomes of laparoscopic sleeve gastrectomy for patients over 65 years old with severe obesity. Surg Obes Relat Dis. 2018;14(7):952-9. https://doi.org/10.1016/j.soard.2018.03.002

26. Marczuk P, Kubisa MJ, Święch M, Walędziak M, Kowalewski P, Major $P$, et al. Effectiveness and safety of Roux-en-Y gastric bypass in elderly patients - systematic review and meta-analysis. Obes Surg. 2019;29(2):361-8. https://doi.org/10.1007/s11695-018-3546-8

27. Bhandari M, Mathur W, Fobi M, Kosta S. Outcomes of bariatric surgery in geriatric patients $\geq 65$ years: single institution study. Obes Surg. 2019;29(5):1470-6. https://doi.org/10.1007/s11695-019-03718-6

28. Susmallian S, Raziel A, Barnea R, Paran H. Bariatric surgery in older adults: should there be an age limit? Medicine (Baltimore). 2019;98(3):e13824. https://doi.org/10.1097/MD.0000000000013824

29. Cunha JB, Fialho MC, Arruda SL, Nóbrega OT, Camargos EF. Clinical and metabolic improvement after bariatric surgery in older adults: a 6-year follow up. J Nutr Heal Aging. 2020. https://doi.org/10.1007/ s12603-020-1406-4

30. Giordano S, Salminen P. Laparoscopic sleeve gastrectomy is safe for patients over 60 years of age: a meta-analysis of comparative studies. J Laparoendosc Adv Surg Tech. 2020;30(1):1-8. https://doi. org/10.1089/lap.2019.0463

31. Wittgrove AC, Martinez T. Laparoscopic gastric bypass in patients 60 years and older: Early postoperative morbidity and resolution of comorbidities. Obes Surg. 2009;19(11):1472-6. https://doi.org/10.1007/ s11695-009-9929-0 
32. Lynch J, Belgaumkar A. Bariatric surgery is effective and safe in patients over 55: a systematic review and meta-analysis. Obes Surg. 2012;22(9):1507-16. https://doi.org/10.1007/s11695-012-0693-1

33. van Rutte PW, Smulders JF, de Zoete JP, Nienhuijs SW. Sleeve gastrectomy in older obese patients. Surg Endosc. 2013;27(6):2014-9. https://doi.org/10.1007/s00464-012-2703-8

34. Burchett MA, McKenna DT, Selzer DJ, Choi JH, Mattar SG. Laparoscopic sleeve gastrectomy is safe and effective in elderly patients: a comparative analysis. Obes Surg. 2015;25(2):222-8. https://doi. org/10.1007/s11695-014-1421-9

35. Vanommeslaeghe H, Deylgat B, van Cauwenberge S, Dillemans B. Laparoscopic Roux-en-Y gastric bypass in the elderly: feasibility, short-term safety, and impact on comorbidity and weight in 250 cases. Surg Endosc. 2015;29(4):910-5. https://doi.org/10.1007/ s00464-014-3751-z

36. Caceres BA, Moskowitz D, O'Connell T. A review of the safety and efficacy of bariatric surgery in adults over the age of 60: 20022013. J Am Assoc Nurse Pract. 2015;27(7):403-10. https://doi. org/10.1002/2327-6924.12235

37. Victorzon M, Giordano S. Bariatric surgery in elderly patients: a systematic review. Clin Interv Aging. 2015;10:1627-35. https://doi. org/10.2147/CIA.S70313

38. Keren D, Matter I, Rainis T. Sleeve gastrectomy in different age groups: a comparative study of 5-year outcomes. Obes Surg. 2016;26(2):28995. https://doi.org/10.1007/s11695-015-1735-2

39. Huang CK, Garg A, Kuao HC, Chang PC, Hsin MC. Bariatric surgery in old age: a comparative study of laparoscopic Roux-en-Y gastric bypass and sleeve gastrectomy in an Asia centre of excellence. J Biomed Res. 2015;29(2):118-24. https://doi.org/10.7555/JBR.29.20140108

40. Pajecki D, Santo MA, Joaquim HD, Morita F, Riccioppo D, Cleva R, et al. Cirurgia bariátrica em idosos: resultados de seguimento de cinco anos. ABCD Arq Bras Cir Dig. 2015;28(Suppl 1):15-8. https://doi. org/10.1590/S0102-6720201500S100006

41. O'Keefe KL, Kemmeter PR, Kemmeter KD. Bariatric surgery outcomes in patients aged 65 years and older at an American society for metabolic and bariatric surgery center of excellence. Obes Surg. 2010;20(9):1199-205. https://doi.org/10.1007/s11695-010-0201-4
42. Quebbemann B, Engstrom D, Siegfried T, Garner K, Dallal R. Bariatric surgery in patients older than 65 years is safe and effective. Surg Obes Relat Dis. 2005;1(4):389-92; discussion 392-3. https://doi. org/10.1016/j.soard.2005.05.003

43. Nelson LG, Lopez PP, Haines K, Stefan B, Martin T, Gonzalez R, et al. Outcomes of bariatric surgery in patients $\geq 65$ years. Surg Obes Relat Dis. 2006;2(3):384-8. https://doi.org/10.1016/j.soard.2006.02.012

44. Kaplan U, Penner S, Farrokhyar F, Andruszkiewicz N, Breau R, Gmora $\mathrm{S}$, et al. Bariatric surgery in the elderly is associated with similar surgical risks and significant long-term health benefits. Obes Surg 2018;28(8):2165-70. https://doi.org/10.1007/s11695-018-3160-9

45. Pajecki D, Santo MS, Kanagi AL, Riccioppo D, Cleva R, Cecconello I. Functional assessment of older obese patients candidates for bariatric surgery. Arq Gastroenterol. 2014;51(1):25-8. https://doi.org/10.1590/ S0004-28032014000100006

46. Goldberg I, Yang J, Nie L, Bates AT, Docimo Jr S, Pryor AD, et al. Safety of bariatric surgery in patients older than 65 years. Surg Obes Relat Dis. 2019;15(8):1380-7. https://doi.org/10.1016/j.soard.2019.05.016

47. Courcoulas A, Coley RY, Clark JM, McBride CL, Cirelli E, McTigue K, et al. Interventions and operations 5 years after bariatric surgery in a cohort from the US National Patient-Centered Clinical Research Network Bariatric Study. JAMA Surg. 2020;155(3):194-204. https:// doi.org/10.1001/jamasurg.2019.5470

48. Pechman DM, Flores FM, Kinkhabwala CM, Salas R, Berk RH, Weithorn $D$, et al. Bariatric surgery in the elderly: outcomes analysis of patients over 70 using the ACS-NSQIP database. Surg Obes Relat Dis. 2019;15(11):1923-32. https://doi.org/10.1016/j.soard.2019.08.011

49. Parrott J, Frank L, Rabena R, Craggs-Dino L, Isom KA, Greiman L. American Society for Metabolic and Bariatric Surgery Integrated Health Nutritional Guidelines for the Surgical weight loss patient 2016 update: micronutrients. Surg Obes Relat Dis. 2017;13(5):727-741. https://doi.org/10.1016/j.soard.2016.12.018

50. Mechanick JI, Youdim A, Jones DB, Garvey WT, Hurley DL, McMahon M, et al. Clinical practice guidelines for the perioperative nutritional, metabolic, and nonsurgical support of the bariatric surgery patient-2013 update: cosponsored by American Association of Clinical Endocrinologists, the Obesity Society, and American Society for Metabolic \& Bariatric Surgery. Obesity (Silver Spring). 2013;21(01):S1-27. https://doi.org/10.1002/ oby.20461 